\title{
Casa-grande e Senzala e o patriarcado: um diálogo crítico com a teoria feminista
}

\section{Casa-grande e Senzala and the patriarchy: a dialogue with critical feminist theory}

Roberta Menezes Sousa*

Resumo: O presente artigo estabelece um diálogo crítico entre a obra CasaGrande e Senzala, de Gilberto Freyre, e a teoria feminista do patriarcado, com o objetivo de apreender a constituição desse sistema, suas bases de sustentação e sua atualização na sociedade brasileira. Em concordância com Heleieth Saffioti, conclui-se que como ferramenta analítica e histórica o patriarcado é uma categoria indispensável para enfatizar e explicar as desigualdades de gênero e como sistema é estruturante da opressão e dominação da mulher, em reforço mútuo com o capitalismo, exigindo para sua superação transformações radicais para eliminar as desigualdades.

Palavras-chaves: Patriarcado. Feminismo. Dominação-exploração.

\begin{abstract}
This article provides a critical dialogue between Casa-grande e Senzala, of Gilberto Freyre, and feminist theory of patriarchy, with the goal of understanding the constitution of this system, their bases of support and its update in Brazilian society. In agreement with Heleieth Saffioti, it is concluded that as historical and analytical tool, patriarchy is an essential to emphasize and explain gender inequalities and how system category is structural oppression and domination of women, mutual reinforcement with capitalism, to overcome demanding radical changes to eliminate inequalities.
\end{abstract}

Keywords: Patriarchate. Feminism. Domination-exploitation.

Recebido em: 11/11/2011. Aceito em: 20/11/2012.

\footnotetext{
"Doutoranda em Serviço Social pela Universidade Federal de Pernambuco. Mestre em Serviço Social pela Universidade Federal de Pernambuco. Graduada em Serviço Social pela Universidade Estadual do Ceará. Professora no curso de Serviço Social do Instituto Federal de Educação, Ciência e Tecnologia do Ceará. E-mail: roberta_menezes@hotmail.com
} 


\section{Introdução}

O presente artigo estabelece um diálogo crítico entre a obra Casa-Grande e Senzala, de Gilberto Freyre, publicada pela primeira vez em 1933, e a teoria feminista, com o objetivo de apreender a constituição do patriarcado, suas bases de sustentação e sua atualização na sociedade brasileira, assim como investigá-lo como ferramenta analítica necessária para enfatizar e explicar as desigualdades de gênero na sociedade capitalista.

Diante da constatação da existência de pouca interlocução entre as teóricas feministas e os autores do pensamento social brasileiro que discutiram o patriarcalismo, buscamos identificar em Casa-Grande e Senzala as bases de constituição e as características do sistema patriarcal no Brasil durante o período colonial, bem como reconstituir também as principais ideias feministas acerca do patriarcado.

Sobre a atualidade do conceito de patriarcado e sua utilização pela teoria e movimento feministas, recorremos às contribuições de Heleieth Saffioti, referência singular nos estudos que articulam feminismo, patriarcado e capitalismo. Safiotti (2004) considera o patriarcado um regime atual que orienta as relações homem-mulher por ser uma expressão de poder político que dá direitos sexuais aos homens sobre as mulheres. Isso se configura como um tipo de hierarquia que contamina todos os espaços da sociedade, possuindo uma base material que representa uma estrutura de poder baseada na ideologia e na violência.

A escolha de Gilberto Freyre justifica-se por ser um dos autores do pensamento social que mais se deteve na análise do patriarcado brasileiro, regime presente na formação da família e da sociedade em geral, indicando em Casa-Grande e Senzala a predominância de relações traduzidas na arbitrariedade masculina por meio do uso da violência sexual contra a mão de obra escrava feminina, como uma das estratégias da colonização portuguesa para aumentar a população escrava.

A importância deste trabalho está na possibilidade de contribuir para a reflexão e o entendimento das condições de permanência e atualização do patriarcado em suas manifestações contemporâneas, enquanto herança que se arrasta desde o período colonial, assim como destacar que, longe de ter sido superado, a sua crítica pelo movimento feminista é pertinente e aponta desafios para a superação de uma sociedade estruturada pelo patriarcado, racismo e capitalismo.

\section{Casa-Grande e Senzala e o patriarcado: es- tabelecendo um diálogo crítico com a teoria feminista}

O sistema patriarcal instituiu-se no Brasil como estratégia de colonização portuguesa, tendo como bases institucionais de dominação a "família rural ou semirrural" (FREYRE, 2006, p. 80) e o regime de escravidão. Uma base agrágria, escravocata e híbrida apresentaram-se, então, como elementos estruturantes para a formação da sociedade brasileira que sob as mãos dos senhores de engenho concentraram-se terras, homens e mulheres. A casa-grande e a senzala, símbolos da formação patriarcal, representaram:

Todo um sistema econômico, social, político: de produção (a monocultura latifundiária), de trabalho (a escravidão), de transporte (o carro de boi, o banguê, a rede, o cavalo); de religião (o catolicismo de família, com capelão subordinado ao pater familias, culto dos mortos etc.), de vida sexual e de família (patriarcalismo polígamo); de higiene do corpo e da casa (o "tigre", a touceira de bananeira, o banho de rio, o banho de gamela, o banho de assento, o lava-pés); de política (o compadrismo) (p. 36).

[...] a história íntima de quase todo brasileiro: da sua vida doméstica, conjugal, sob o patriarcalismo escravocrata e polígamo; da sua vida de menino, do seu cristianismo reduzido à religião de família e influenciado pelas crendices da senzala [...] Nas casas-grandes foi até hoje onde melhor se exprimiu o caráter brasileiro: a nossa continuidade social. (p. 44).

Freyre (2006), ao discorrer sobre o sistema patriarcal de colonização portuguesa, acrescenta que ao lado do sistema de produção econômica com base na monocultura latifundiária, a relação entre os brancos e "as raças de cor" (p. 32) foi condicionada tanto por uma "escassez de mulheres brancas [criando] zonas de confraternização entre vencedores e vencidos, entre senhores e 
escravos" (p. 33), como também por certa preferência sexual.

A ideia recorrente na narrativa de Freyre, em diversas passagens de Casa-Grande e Senzala, é de harmonia e naturalização dessas relações sexuais entre colonos, nativos e africanos. A miscigenação ou mistura racial é caracterizada como um processo de democracia racial e de formação do povo brasileiro, se não vejamos:

A miscigenação que largamente se praticou aqui corrigiu a distância social que de outro modo se teria conservado enorme entre casagrande e a mata tropical; entre a casa-grande e a senzala. O que a monocultura latifundiária e escravocrata realizou no sentido de aristocratização, extremando a sociedade brasileira em senhores e escravos [...] foi em grande parte contrariado pelos efeitos sociais da miscigenação. A índia e a negra-mina a princípio, depois a mulata, a cabrocha, a quadrarona, a oitavona, tornando-se caseiras, concubinas e até esposas legítimas dos senhores brancos, agiram poderosamente no sentido da democratização social do Brasil. (FREYRE, 2006, p. 33).

A luxúria dos indivíduos soltos sem família, no meio da indiada nua, vinha a servir a poderosas razões de Estado no sentido de rápido povoamento mestiço da nova terra. $\mathrm{E}$ é certo que sobre a mulher gentia fundou-se e desenvolveu-se através dos séculos $\mathrm{XVI}$ e $\mathrm{XVII}$ o grosso da sociedade colonial, em um largo e profundo mestiçamento [...] $\mathrm{O}$ europeu saltava em terra escorregando em índia nua [...] As mulheres eram as primeiras a se entregarem aos brancos, as mais ardentes indo esfregar-se nas pernas desses que supunham deuses. Davam-se ao europeu por um pente ou um caco de espelho. (p. 161).

Entre culturas de interesses e tendências tão antagônicos era natural que o contato se verificasse com desvantagens para ambas. Apenas um conjunto especialíssimo de circunstâncias impediu, no caso do Brasil, que europeus e indígenas se extremassem em inimigos de morte, antes se aproximassem como marido e mulher, como mestre e discípulo, daí resultando uma degradação de cultura por processos mais sutis e em ritmo mais lento do que em outras partes do continente. (p. 230).
Ao colocarmos nossas lentes lilases ${ }^{1}$ para visualizar de maneira mais crítica a obra Casa-grande e Senzala, podemos perceber que diferentemente do que relata Gilberto Freyre, a expansão numérica do povoamento brasileiro praticamente se deu pela dominação e arbitrariedade masculina no uso da violência sexual contra as negras e índias. Saffioti (2004), ao tratar sobre a gênese do escravismo, afirma que o racismo $e$ o sexismo são irmãos gêmeos e ambos se situam na base do escravismo:

Quando um povo conquistava outro, submetia-o a seus desejos e a suas necessidades. Os homens eram temidos, em virtude de representarem grande risco de revolta, já que dispõem, em média, de mais força física que as mulheres, sendo, ainda, treinados para enfrentar perigos. Assim, eram sumariamente eliminados, assassinados. As mulheres eram preservadas, pois serviam a três propósitos: constituíam força de trabalho, importante fator de produção em sociedades sem tecnologia ou possuidoras de tecnologias rudimentares; eram reprodutoras desta força de trabalho, assegurando a continuidade da produção e da própria sociedade; prestavam (cediam) serviços sexuais aos homens do povo vitorioso. (SAFFIOTI, 2004, p. 124).

Freyre (2006) responsabiliza o sistema social e econômico que funcionou na aliança entre escravidão e "depravação sexual", "criando nos proprietários de homens imoderado desejo de possuir o maior número possível de crias" ( $p$. 399), ao considerarem o ventre gerador a parte mais produtiva da propriedade escrava, com a finalidade de produzir mais mão de obra escrava.

De acordo com Saffioti (2004), o racismo, base do escravismo, nasceu no mesmo momento que o sexismo, cada um presidido por uma lógica em separado, mas quando integrados ao nó, acrescida da classe social, enovelados e presididos por uma lógica contraditória, cada uma dessas contradições adquire relevos distintos, ao considerar as circunstâncias históricas.

\footnotetext{
${ }^{1}$ Utilizamos a palavra lentes para dar uma ideia da necessidade de uma aproximação maior com o objeto em visualização, com função corretiva. E lente lilás por esta ser a cor que representa a luta das mulheres por igualdade de gênero e transformação societária.
} 
No regime patriarcal, as mulheres são "objetos de satisfação sexual dos homens, produtoras de herdeiros, de força de trabalho e de novas reprodutoras" (SAFFIOTI, 2004, p. 105), o que envolve uma série de prestações de serviços sexuais aos seus dominadores, com base em relações hierarquizadas entres seres socialmente desiguais, uma espécie de pacto masculino para garantir a opressão às mulheres.

Em algumas passagens de Casa-Grande e Senzala é possível visualizar com mais nitidez a violência praticada pelos senhores rurais, por seus filhos e pelas mulheres brancas contra as mulheres negras, como observamos na passagem a seguir: "senhores mandando queimar vivas, em fornalhas de engenho, escravas prenhes, as crianças estourando ao calor das chamas" (FREYRE, 2006, p. 46). Em outra citação, outro relato revela a predominância de relações sociais violentas:

Quanto à maior crueldade das senhoras que dos senhores no tratamento dos escravos é fato geralmente observado nas sociedades escravocratas [...] Sinhás-moças que mandavam arrancar os olhos de mucamas bonitas e trazê-los à presença do marido, à hora da sobremesa, dentro da compoteira de doce e boiando em sangue ainda fresco. Baronesas já de idade que por ciúme ou despeito mandavam vender mulatinhas de quinze a velhos libertinos. Outras que espatifavam a salto de botina dentaduras de escravas; ou mandavam-lhe cortar os peitos, arrancar as unhas, queimar a cara ou as orelhas. Toda uma série de judiarias. (FREYRE, 2006, p. 420-421).

Nas linhas em que trata da sifilização no Brasil, fica nítida a violência sexual praticada contra crianças e adolescentes do sexo feminino:

A contaminação em massa verificou-se nas senzalas coloniais. A "raça inferior", a que se atribui tudo que é handicap no brasileiro, adquiriu da "superior" o grande mal venéreo que desde os primeiros tempos de colonização nos degrada e diminui. Foram os senhores das casas-grandes que contaminaram de lues as negras das senzalas. Negras tantas vezes entregues virgens, ainda molecas de doze e treze anos, a rapazes brancos já podres da sífilis das cidades. Porque por muito tempo dominou no Brasil a crença de que para o sifilítico não há melhor depurativo que uma negrinha virgem. (FREYRE, 2006, p. 400).
Mas no ambiente voluptuoso das casas-grandes, cheias de crias, negrinhas, molecas, mucamas, é que as doenças venéreas se propagaram mais à vontade, através da prostituição doméstica - sempre menos higiênica que a dos bordéis. Em 1845 Lassance Cunha escrevia que o brasileiro não ligava importância à sífilis, doença "como que hereditária e tão comum, que o povo a não reputa um flagelo, nem tão pouco a receia". Doença como que doméstica, de família, como o sarampo e os vermes. (p. 401).

A justificativa para abusos dos brancos sobre os negros, o autor nos diz que deve ser procurada "nas condições econômicas e sociais favoráveis ao masoquismo e ao sadismo criadas pela colonização portuguesa - colonização, a princípio, de homens quase sem mulher - e no sistema escravocrata de organização agrária do Brasil; na divisão da sociedade em senhores todo-poderosos e em escravos passivos". (FREYRE, 2006, p. 404).

Ao contrário desta passividade, indícios de resistência podem ser visualizados nos relatos de Joaquim Nabuco (AGUIAR, 2000), quando menciona a recusa das negras em dar a luz aos filhos provenientes de estupros praticados pelos senhores brancos, usando ervas daninhas e venenos para provocar o aborto. Segundo Saffiotti (2004, p. 130), "o fato do patriarcado ser um pacto entre os homens não significa que a ele as mulheres não oponham resistência". Tal autora conclui que as relações de dominação-exploração são marcadas por resistências, lutas, conflitos, vinganças, sabotagem, boicote e luta de classes.

Em relação à violência perpetrada pelos senhores brancos contra índias e negras, para garantir a reprodução da mão de obra e o povoamento, Carneiro (2001 apud ÁVILA, 2001) vai denominar de estupro colonial, permanecendo ainda atuantes no imaginário social as teses de democracia racial, dada a mestiçagem do povo brasileiro. Sobre a violência colonial, a autora afirma que "está na origem de todas as construções de nossa identidade nacional, estruturando o decantado mito da democracia racial latino-americana, que no Brasil chegou até as últimas consequências". (CARNEIRO, 2001).

A tese da democracia racial é questionada também por Marilena Chauí (2007). Destaca 
em seus estudos, a força persuasiva e de renovação do mito generalizado de uma crença de que o Brasil é um país sem preconceitos e discriminações de raça, classe ou de credo, de povo pacífico, ordeiro, generoso, alegre, sensual, acolhedor. Segundo Chauí, essa imagem positiva do país foi gerada por um mito que serve como uma espécie de solução imaginária para tensões, conflitos e contradições de uma realidade permeada de contrastes, com determinações socioeconômicas, históricas e políticas.

Mesmo diante da existência de diferentes graus de domínio exercidos pelos homens sobre as mulheres e contextos sócio-históricos particulares, a natureza do patriarcado é a mesma, sendo imprescindível historicizar e contextualizar a dominação masculina para compreender e dimensioná-lo adequadamente.

Para compreender as condições de permanência e atualização do patriarcado, o próximo tópico apresenta, de forma sucinta, a colaboração da teoria feminista às discussões sobre o tema, bem como suas manifestações contemporâneas na sociedade brasileira, mostrando que, longe de ter sido superado, o patriarcado dá sinais de que permanece vivo.

\section{O patriarcado e as teorias feministas}

As diversas correntes do pensamento feminista, após 1960, compartilharam alguns pressupostos sobre a subordinação feminina, dentre eles a afirmação do caráter fundamentalmente social das desigualdades entre homens e mulheres. A categoria patriarcado passa a ser utilizada nos estudos sobre a mulher pelas feministas radicais na década de 1970 para explicar e denunciar as relações de dominação masculina sobre as mulheres, designando:

Uma formação social em que os homens detem o poder, ou ainda, mais simplesmente, o poder é dos homens. Ele é, assim, quase sinônimo de "dominação masculina" ou de opressão das mulheres. Essas expressões, contemporâneas dos anos 70 , referem-se ao mesmo objeto, designado na época precedente pelas expressões "subordinação" ou "sujeição" das mulheres, ou ainda "condição feminina". (DELPHY, 2009, p. 173).

Antes do século XIX, patriarcado e patriarcas tinham um sentido religioso, indicando os primeiros chefes de família que viveram antes ou depois do Dilúvio (DELPHY, 2009). Na concepção weberiana, refere-se a uma forma de dominação ${ }^{2}$ de caráter tradicional exercida por um indivíduo normalmente determinado segundo regras fixas de sucessão, em que o senhor depende, em grande parte, da vontade de obedecer dos associados, uma vez que não possui um quadro administrativo (WEBER, 2000).

Porém, o uso do conceito de patriarcado pelas teorias feministas distancia-se da concepção de Weber, pois esse autor inscreve a legitimação da dominação "recorrendo a fatos sempre redutíveis à subjetividade" (SAFFOTI, 2004, p. 99). Para Saffioti, o conceito de dominação (masculina) tem que estar associado ao de exploração (capitalista), porque a realidade é una, indivisível, não havendo territórios distintos para estas duas dimensões.

Nos marcos das reivindicações por direitos iguais, a luta das mulheres no século XIX e início do XX lançou uma pergunta central ao feminismo sobre a origem, subordinação e manutenção da opressão contra a mulher, contribuindo para a criação de um sujeito político coletivo e estratégias para por fim à subordinação feminina.

Mesmo com as diversas correntes do pensamento feminista e suas diferenças, as abordagens teóricas desenvolvidas pós-1960 compartilharam algumas ideias centrais, a exemplo da desnaturalização da subordinação feminina, a sua universalidade e a construção social baseada nas desigualdades entre mulheres e homens. Algumas divergências entre as vertentes feministas que diziam respeito a questões relativas às origens e causas da opressão e aos mecanismos para livrarem-se da dominação masculina (PISCITELLI, 2004).

Para as teóricas do patriarcado, as muIheres eram oprimidas pelo simples fato de serem mulheres. As experiências de opressão

\footnotetext{
2 Weber chama de dominação a probabilidade de encontrar obediência para ordens específicas ou não, dentro de um determinado grupo de pessoas, porém não é toda forma de exercer poder ou influência sobre as pessoas que pode ser caracterizada como dominação. Esta vai pressupor submissão, que varia desde formas inconscientes, baseadas em hábitos, até formas racionais. Para haver uma relação autêntica de dominação deve ter o mínimo de vontade de obedecer, de interesse na obediência, requerendo um quadro administrativo em que possa confiar cuja obediência possa contar para uma ação, na execução de disposições gerais e ordens concretas. (WEBER, 2000).
} 
vivenciadas por elas ocorriam no cotidiano, nas relações mais íntimas, permeadas de poder masculino. Afirmavam que todas as mulheres, independentemente da classe social, sofriam opressão e que esta fazia parte da experiência feminina. Suas questões políticas não podiam, em grande parte, ser enquadradas no interior do capitalismo e do Estado, por não estarem relacionadas com a esfera pública. Para o feminismo de então, estas relações eram exclusivamente políticas, e o patriarcado seria, portanto, a expressão desse poder. Com a definição de que o pessoal é político:

[...] as feministas procuraram desvendar a multiplicidade de relações de poder presentes em todos os aspectos da vida social e isto as levou a tentar agir nas mais diversas esferas. Em termos teóricos, elas trabalharam com a ideia global e unitária de poder, o patriarcado, numa perspectiva em que cada relacionamento homem/mulher deveria ser visto como uma relação política (PISCITELLI, 2004, p. 47).

Acreditavam que as origens da subordinação feminina localizavam-se nos papéis desempenhados por homens e mulheres no processo de reprodução. A origem da dominação masculina sobre as mulheres estava nas suas características biológicas no que diz respeito ao aspecto reprodutivo. A sua libertação seria possível, segundo Shulamith Firestone, com os avanços tecnológicos que proporcionariam a eliminação das funções de reprodução da espécie do corpo das mulheres (apud SCOTT, 1989). Eliminar a dominação dos homens pressupunha derrotar o patriarcado, e isso só seria possível quando as mulheres adquirissem controle sobre a sua reprodução. Para outras feministas radicais, a sexualidade seria a chave do patriarcado, em uma relação na qual a mulher figuraria como objeto e o homem como sujeito. A dominação aparece na forma de reificação sexual feminina.

As feministas ligadas ao campo socialista analisaram essa relação sob outra ótica, qual seja, a partir das origens da opressão na divisão sexual do trabalho no momento do surgimento das classes sociais e da propriedade privada, com uma base material assentada na sociedade classista. Outras vertentes do feminismo socialista criticaram esse conjunto de ideias, porque mesmo em países socialistas as hierarquias de gênero persistiram. As causas originárias da opressão estariam na associação entre capitalismo e patriarcado.

$\mathrm{Na}$ academia, ao passo que as feministas iniciaram a revisão das produções disciplinares e consolidaram os estudos da mulher, a partir de conceitos e categorias utilizados pelo pensamento feminista, começaram a ser questionadas, sobretudo em relação ao patriarcado como categoria de análise. Devido aos problemas desta categoria referentes à apreensão da historicidade da condição feminina e à compreensão das diversas formas de discriminação organizadas pelas relações sociais, de forma contextualizada,

As sociólogas feministas criaram termos como "relações de sexo", que são unicamente francesas e intraduzíveis em outra língua. Esse termo, agora o mais utilizado em Sociologia, foi inicialmente concebido como uma alternativa a "patriarcado", julgado insatisfatório, e mais tarde ao termo "gênero" (DELPHY, 2009, p. 177).

Uma outra objeção a "patriarcado" é sua generalidade: pode-se reprová-lo por universalizar uma forma de dominação masculina situada no tempo ou no espaço; ou então correr o risco de cair na falha inversa, de ser trans-histórico e transgeográfico. Alguns autores precisam o tempo e a localização de seu uso (DELPHY, 1998), mas o uso atemporal também é legítimo, se não conceder poder explicativo ao termo e "patriarcado" for empregado de maneira descritiva. (p. 177).

Se por um lado o patriarcado foi um conceito descartado em sua propriedade de apreensão da dominação masculina sobre as mulheres, o seu uso não foi totalmente abandonado. No Brasil, Saffioti foi uma das autoras que trabaIhou o patriarcado como forma específica das relações de gênero, regime que se ancora "em uma maneira de os homens assegurarem, para si mesmos e para seus dependentes, os meios necessários à produção diária e à reprodução da vida". (SAFFIOTI, 2004, p. 105).

Em face da elaboração de outras ferramentas conceituais, como a categoria gênero, desenvolvidas para desnaturalizar a opressão feminina e superar problemas quanto à utilização de categorias centrais nos estudos da mulher, Saffioti, recorrendo a Paterman (1993), manifesta sua preocupação ao abandono do: 
[...] único conceito que se refere especificamente à sujeição da mulher, e que singulariza a forma de direito político que todos os homens exercem pelo fato de serem homens. Se o problema não for nomeado, o patriarcado poderá muito bem ser habilmente jogado na obscuridade, por debaixo das categorias convencionais da análise política. [...] Grande parte da confusão surge porque "patriarcado" ainda está por ser desvencilhado das interpretações patriarcais sobre o patriarcado. Abandonar o conceito significaria a perda de uma história política que ainda está para ser mapeada. (PATERMAN, 1993 apud SAFFIOTI, 2004, p. 55).

O patriarcado, acrescenta Saffioti (2004), enovelado pela clivagem de classes sociais e racismo, "apresenta não apenas uma hierarquia entre categorias de sexo, mas traz também, em seu bojo, uma contradição de interesses" ( $p$. 107), não apenas conflitantes, mas contraditórios. Este sistema "não se resume a um sistema de dominação, modelado pela ideologia machista. Mais do que isto, ele é também um sistema de exploração" (p. 50), expande-se por todo corpo social, tanto na esfera privada como pública, e sua máquina pode ser acionada por qualquer um (a), inclusive pelas mulheres imbuídas da ideologia que envolve o patriarcado. De acordo com a definição de Saffioti (2004), o patriarcado:

1. não se trata de uma relação privada, mas civil;

2. dá direitos sexuais aos homens sobre as mulheres, praticamente sem restrição;

3. configura um tipo hierárquico de relação, que invade todos os espaços da sociedade;

4. tem uma base material;

5. corporifica-se;

6. representa uma estrutura de poder baseada tanto na ideologia quanto na violência. (p. 57-58).

As expressões deste sistema de dominação-exploração na contemporaneidade mostram que, longe de ter sido abolido, atualiza-se em um processo contínuo de transformação ao longo da história da formação social brasileira. Não obstante os avanços dos direitos das mulheres, muitos são os desafios para o movimento feminista e de mulheres na atual conjuntura. Em concordância com Saffioti (2004), sustenta-se que a base material do patriarcado não foi destruída,

[...] que não basta que uma parte das mulheres ocupe posições econômicas, políticas, religiosas etc., tradicionalmente reservadas aos homens. [...] qualquer que seja a profundidade da dominação-exploração da categoria mulheres pela dos homens, a natureza do patriarcado continua a mesma. (p. 104).

O sistema patriarcal se faz presente na prática da violência contra as mulheres; no turismo, tráfico e exploração sexual; no controle do corpo e de sua sexualidade; na participação desigual de homens e mulheres no mercado de trabalho e no trabalho doméstico, bem como a precariedade e a flexibilização que atingem em maior medida as mulheres; nas desigualdades presentes na participação política, na feminização da pobreza, dentre outras expressões.

\section{Violência}

A violência contra as mulheres é uma das expressões mais explícitas das desigualdades de poder entre homens e mulheres, em geral legitimada socialmente e assumindo múltiplas formas, que englobam "todos os atos que, por meio de ameaça, coação ou força, Ihes infligem, na vida privada ou pública, sofrimentos físicos, sexuais ou psicológicos com finalidade de intimidá-las, puni-las, humilhá-las, atingi-las na sua integridade física e na sua subjetividade (ALEMANY, 2009, p. 271)".

Geralmente os agressores são seus maridos; namorados; pais; parentes e colegas de trabalho. Segundo Alemany (2009, p. 271), todas as mulheres são vítimas em potencial, podendo serem privadas "da sua liberdade de ir e vir, do seu sentimento de segurança, da sua autoconfiança, de sua capacidade de construir relacionamentos, de seu gosto pela vida".

Muitos são os esforços empreendidos pelas feministas no desenvolvimento de estudos teóricos sobre as violências praticadas contra as mulheres, para se opor aos "estudos criminológicos que, com seus preconceitos androcêntricos, privilegiam as teorias vitimológicas (ou interacionistas), que fazem da relação entre a vítima 
e o autor um elemento explicativo fundamental" (ALEMANY, 2009, p. 272).

Mesmo com todas as lutas empreendidas pelo movimento feminista para forçar o Governo brasileiro a combater a violência contra a mulher, mediante mudanças nas legislações punitivas e na criação de estruturas de apoio às vítimas, essa pauta ainda se constitui como uma das principais e mais desafiantes bandeiras para o feminismo. Waiselfisz (2012) aponta que em 2007 houve uma queda significativa dos homicídios contra as mulheres, provavelmente em decorrência da aprovação da Lei Maria da Penha em 2006. Porém, em 2008 as taxas subiram novamente e até ultrapassaram os anos anteriores. No século atual já morreu praticamente a metade das mulheres assassinada entre o período de 1980 a 2011 . Outro dado que merece destaque é a distribuição etária dos homicídios de mulheres, quando em 2011 apresentou uma espécie de pico, embora irregular concentrada na faixa de 17 aos 31 anos de idade.

\section{Tráfico e exploração sexual}

A globalização e o crescimento da indústria do sexo são fenômenos estreitamente imbricados, e as análises sobre o capitalismo contemporâneo não consideram os impactos desta indústria nas sociedades e relações sociais (POULIN, 2005). Ainda segundo esse autor, mundialmente, a prostituição gerou lucros de 60 bilhões de euros e a pornografia 52 bilhões, em 2002. O tráfico de pessoas para fins sexuais atinge cifras que variam de 7,8 a 13,5 bilhões/ ano, enquanto agências de turismo sexual na internet faturam um bilhão de euros/ano.

De acordo com a ONU (Organização das Nações Unidas), o Brasil é hoje o maior "exportador" de mulheres escravas da América do Sul vítimas do crime organizado. Anualmente, muitas vezes sob a forma de mentiras e violência, de falsas promessas de trabalho e de uma vida melhor, as mulheres deixam suas regiões para buscarem alternativas concretas de sobrevivência. Algumas delas saem do país sabendo que vão trabalhar como prostitutas, mas não imaginam que se tornarão escravas sexuais, exploradas sexual e economicamente nos países de destino, com jornadas de trabalho diário entre 10 e 13 horas, vida clandestina, desconhecimento do idioma lo- cal, incentivo ao consumo de drogas, cobranças abusivas das despesas de passagem, alimentação e moradia. (REPÓRTER BRASIL, 2012).

\section{Controle do corpo e sexualidade}

A legalização do aborto é também um dos obstáculos enfrentados pelas mulheres para decidirem de maneira autônoma sobre seus próprios corpos. No Brasil, exceto nas situações de risco de vida da gestante e gravidez que resulta de estupro, a prática do aborto é criminalizada ${ }^{3}$, fazendo que as mulheres frequentemente recorram aos serviços clandestinos, responsáveis por inúmeras sequelas à sua saúde e, muitas vezes, pela própria morte, especialmente das mulheres pobres, negras e jovens.

O crescimento dos fundamentalismos religiosos nas esferas nacional e internacional revela a forte influência que estes possuem sobre o Governo brasileiro e sobre os padrões culturais que vigoram na sociedade, reintroduzindo a repressão sexual, a homofobia, a violência e a intolerância como parte de uma ordem social patriarcal que se apresenta de diferentes maneiras, correspondendo a uma ameaça direta à laicidade do Estado e aos direitos das mulheres.

Ao negá-las o direito de decidir sobre a continuidade ou interrupção de uma gravidez, o Estado brasileiro retira-Ihes a capacidade eminentemente humana de consciência, de discernimento, de criar valores e de escolher entre eles enquanto seres éticos e que, portanto, agem eticamente. Ou seja, é negada a liberdade - fenômeno puramente social e constitutivo do ser social - como possibilidade de escolha entre alternativas reais, como ato de consciência.

O estupro é outra manifestação do sistema de dominação-exploração para o exercício do controle do corpo e da sexualidade das mulheres. Configura-se como um tipo de hierarquia que contamina todos os espaços da sociedade e expressa o poder político que dá direitos sexuais aos homens sobre as mulheres. Em cinco anos,

\footnotetext{
${ }^{3}$ De acordo com o artigo 128, do Decreto-lei n. 2.848 de 07 de dezembro de 1940, do Código Penal, não se pune o aborto praticado por médicos nos casos de não haver outro meio de salvar a vida da gestante e em caso de gravidez resultante de estupro. Em 2012, por decisão do Supremo Tribunal Federal, o aborto é permitido se o feto for anencefálico, que descreve a prática como "parto antecipado" para fim terapêutico.
} 
os registros de casos de estupro no país aumentaram em 168\%, segundo o Fórum de Segurança Pública (PORTAL R7 NOTÍCIAS, 2013).

\section{Trabalho}

No âmbito do trabalho, os estudos de gênero sobre a questão apontam que as mulheres fazem parte do setor mais pobre e precário da classe trabalhadora. Para Hirata (2000), as desigualdades ligadas ao sexo/gênero persistem e se agravam, em particular, no mundo do trabalho. Se em âmbito mundial o emprego assalariado e o trabalho remunerado das mulheres cresceram a partir de 1990, este crescimento acompanhou uma maior precarização e vulnerabilidade, no que diz respeito às desigualdades sociais, condições de trabalho e saúde e à flexibilização das relações de trabalho.

O crescimento do emprego feminino deu-se principalmente no setor informal da economia, que emprega predominantemente as mulheres destituídas de quaisquer direitos trabalhistas e que recebem em média metade do salário dos homens e as mulheres negras, a metade do que ganham as mulheres brancas. Nos países desenvolvidos, no setor industrial:

O salário médio das mulheres representa três quartos do salário masculino, em parte por uma menor qualificação, mas também em razão de uma distribuição desigual pelos ramos econômicos e postos ocupados [...] Assim, a divisão sexual do trabalho permanece no centro das desigualdades de estatuto e de salário. Elas foram reforçadas, ademais, pelas políticas de ajuste estrutural. (HIRATA, 2000, p. 5).

No Brasil, a ocupação das mulheres continua concentrada no setor de serviços pessoais, administração pública, saúde e educação, representando $86 \%$. Cerca de $80 \%$ das mulheres que trabalham recebem até dois salários mínimos e $15 \%$ permanecem desempregadas, contra $11 \%$ do desemprego masculino (JARDIM, 2011). As trabalhadoras domésticas chegam a 5 milhões, com idade média de 25 anos, correspondendo a "uma parcela empobrecida e precarizada da juventude no mercado de trabalho, $60 \%$ tem jornada semanal maior que $44 \mathrm{~h}, 65 \%$ está na informalidade". (p. 18).
Ainda se encontram responsáveis pela dedicação maior de horas para o trabalho doméstico não remunerado, configurando-se como um dos obstáculos para a sua inserção no mercado de trabalho. A média de tempo gasto com os serviços em casa e cuidado com os filhos representa em média cerca de $22 \mathrm{~h}$ a $27 \mathrm{~h}$ semanais.

$\mathrm{Na}$ indústria de confecção é considerável o aumento das terceirizações nas empresas de grande porte e o retorno do trabalho em domicílio, nas pequenas oficinas de costura, forma de trabalho escravo em cooperativas. Mendonça (2011) constata que estas formas de subcontratação impedem o acionamento de uma representação sindical e a ação coletiva destas trabalhadoras.

No setor de serviços, em específico no telemarketing, $70 \%$ das trabalhadoras são mulheres, universitárias, com idade entre 22 e 30 anos. A utilização de terceirizadas neste setor provocou muitos ataques e mudanças nos direitos trabaIhistas. O trabalho ocorre:

Sob uma pressão absurda, dentro de módulos de trabalho denominados "baias", onde a fiscalização eletrônica está presente desde a movimentação no posto de atendimento até o registro do ritmo de trabalho. Tudo é registrado pelo software que vai muito além do antigo relógio de ponto. Lá se registram as pausas, o tempo das saídas para refeição, café, ida ao banheiro, etc. A produtividade e maisvalia é medida pelo número de atendimentos e o tempo que se leva em cada um deles. (MENDONÇA, 2011, p. 20).

$\mathrm{Na}$ medida em que o capital tem incorporado o trabalho das mulheres, a flexibilização e a precarização da mão de obra feminina apontam para tendências do trabalho deste segmento no contexto de crise econômica e desemprego em massa. Crescem os trabalhos precários, mal remunerados, em tempo parcial, temporários, informais, sem proteção social preservando a distância entre homens e mulheres no interior da classe trabalhadora.

\section{Participação política}

Segundo os estudos acerca das relações gênero e política, a entrada das mulheres no espaço público pode se dar de duas maneiras: ou de maneira subordinada a um padrão em que 
são colocadas como intrusas e são adequadas às normas dominantes; ou de maneira que rompem com o limite tradicional de seu papel de gênero feminino (DELGADO, 2000, p. 44). Essa entrada é marcada por uma identidade que se baseia no cuidado e nas relações afetivo-sociais, ambas desvalorizadas social e politicamente, pois são consideradas funções complementares ao trabalho dos homens, o que "aprofunda uma divisão sexual do trabalho que determina as formas com que as mulheres se inserem no espaço público, privando-as das condições de exercer, em igualdade de condições com os homens, a participação social e política". (GODINHO, 1991, p. 37).

Na política, o padrão de socialização da militância ainda é essencialmente masculino. Há critérios de socialização, credenciamento e reconhecimento fundados em um modelo de militância ainda hegemônico, que, quando analisado sob o ponto de vista de gênero, permite enxergar diferenças e desigualdades nas vivências de homens e mulheres. Este padrão é identificado e associado às características historicamente atribuídas aos homens, as quais se mantêm e se reproduzem nos espaço políticos, contribuindo para perpetuar a discriminação e a opressão de gênero, que além de se pautar em determinações culturais, também "se embasa em questões materiais e opera na vida cotidiana, nas relações que se estabelecem entre os dois sexos, de forma individual, na família, perpassando todas as estruturas da sociedade". (GODINHO, 1991, p. 39).

Como um dos mecanismos de superação da exclusão das mulheres da política, o movimento feminista propõe a efetivação da paridade nos processos eleitorais, com listas de candidaturas com alternância paritária entre os sexos e a garantia de divisão igualitária de recursos financeiros e tempo na TV para as campanhas das mulheres. Atualmente o Brasil está na $86^{\circ}$ posição no que se refere ao acesso das mulheres ao Poder Executivo, parlamentos e ministérios.

\section{Assistência Social}

Para as mulheres das camadas mais empobrecidas, o Estado brasileiro passou a adotar ações e programas de combate à pobreza aos moldes dos organismos internacionais, sem apontar soluções reais para os problemas vivenciados pela população pobre, com um significativo retrocesso no campo dos direitos sociais, em especial quando se trata do aumento do desemprego e da precarização do trabalho, conjugado à perda de vínculos com a previdência social.

A pauperização passa a ser tratada como uma questão de assistência (MOTA, 2008) e as mulheres corresponsabilizadas pelo "êxito e desenvolvimento dos programas de assistência social que têm a renda mínima como benefício" (DUQUE-ARRAZOLA, 2008, p. 243-244), com o reforço e aumento das responsabilidades e tarefas na reprodução das famílias, ao serem consideradas melhores gestoras dos recursos governamentais e cuidadoras das famílias.

Diante desse quadro, em concordância com Saffioti (2004, p. 107), "a contradição não encontra solução neste regime. Ela admite a superação, o que exige transformações radicais no sentido da preservação das diferenças e da eliminação das desigualdades". Para as transformações radicais na sociedade faz-se necessário o resgate de um feminismo revolucionário. A eliminação das desigualdades entre mulheres e homens deve ser parte fundamental de um projeto radical de mudanças na sociedade, sem opressões e exploração, sendo imprescindível a articulação entre projeto societário e projeto feminista na luta pela liberação das mulheres e pela igualdade substantiva, como possibilidade de rompimento com a sociedade patriarcal-racista-capitalista.

\section{Considerações finais}

Gilberto Freyre, na obra Casa-Grande e Senzala, deu visibilidade e abordou muitas questões referentes às mulheres e às relações de gênero no Brasil Colonial: a vida sexual, a violência, o adultério, a prostituição, a virgindade, os padrões de feminilidade, paternidade, a higiene corporal, dentre outros aspectos.

Sua narrativa proporcionou a compreensão das diversas condições de vida das mulheres de acordo com a classe ou condição social, raça e geração, fornecendo subsídios para compreender a constituição da sociedade patriarcal no Brasil, no que concerne à vida pública e privada.

Como categoria adotada pela teoria e movimento feminista, o patriarcado não explica todas as desigualdades de gênero presentes

70 Emancipação, Ponta Grossa, 14(1): 61-72, 2014. Disponível em <http://www.revistas2.uepg.br/index.php/emancipacao> 
ainda na sociedade brasileira, mas é uma ferramenta de análise e explanação relevante dos efeitos da herança colonial e de seus mecanismos de reprodução presentes nas formas de sociabilidade do país.

Longe de ter sido superado, o patriarcalismo precisa ser explicado em suas transformações e expressões na sociedade brasileira atual. Como é reinventado, sustentado e perpetuado o patriarcado na contemporaneidade? Quais as manifestações do patriarcado e as formas de resistência a este sistema na sociedade brasileira?

Corroboramos com o pensamento de Saffioti (2004) segundo o qual o conceito de patriarcado ainda é uma ferramenta histórica e analítica necessária para enfatizar e explicar as desigualdades de gênero. É estruturante da opressão e dominação da mulher como sistema, em reforço mútuo com o capitalismo, e para sua superação exige transformações radicais para preservar as diferenças e eliminar as desigualdades.

\section{Referências}

AGUIAR, N. Patriarcado, sociedade e patrimonialismo. Sociedade e Estado [online], Brasília, v. 15, n. 2, p. 330, 2000.

ALEMANY, Carme. Violências. In: HIRATA, H. et al. (Orgs.). Dicionário crítico do feminismo. São Paulo: Ed. UNESP, 2009.

ALMEIDA, J. P. de. As multifaces do patriarcado: uma análise das relações de gênero nas famílias homoafetivas. 2010. 116 f. Dissertação (Mestrado em Serviço Social) - Universidade Federal de Pernambuco, Recife, 2010.

ÁVILA, M. B. Feminismo, cidadania e transformação social. In: ÁVILA, M. B. et al. Textos e imagens do feminismo: mulheres construindo a igualdade. Recife: SOS Corpo, 2001.

CARNEIRO, S. Enegrecer o feminismo: a situação da mulher negra na América latina a partir de uma perspectiva de gênero. Disponível em: <http://www. unifem.org.br/sites/700/710/00000690.pdf.> Acesso em: 12 mar. 2013.

CHAUÍ, M. Brasil: mito fundador e sociedade autoritária. História do povo brasileiro. São Paulo: Ed. Fundação Perseu Abramo, 2007.

DELGADO, M. do C. G. Desigualdade de gênero e participação política das mulheres: a experiência do partido dos trabalhadores. 2000.154 f. Dissertação (Mestrado em Ciências Sociais) - Pontifícia Universidade Católica de São Paulo, São Paulo, 2000.

DELPHY, C. Patriarcado (Teorias do). In: HIRATA, H. et al. (Orgs.). Dicionário crítico do feminismo. São Paulo: Ed. UNESP, 2009.

DUQUE-ARRAZOLA, L. S. O sujeito feminino nas políticas de assistência social. In: MOTA, A. E. (Org.). O mito da assistência social: ensaios sobre Estado, política e sociedade. 2. ed. rev. e ampl. São Paulo: Cortez, 2008.

FREYRE, G. Casa-grande e senzala: formação da família brasileira sob o regime da economia patriarcal. São Paulo: Global, 2006.

GODINHO, Tatau. Mulher na direção. Teoria e Debate, São Paulo, p.36-9, mai.1991.

HIRATA, H. S. Divisão sexual do trabalho: novas tendências e problemas atuais. Gênero no mundo do trabalho. I Encontro de Intercâmbio de experiências do Fundo de Gênero no Brasil, Brasília: CIDA: 2000.

JARDIM, Danielle. Retratos da precarização: reflexões sobre o trabalho feminino no capitalismo contemporâneo. In: Revista Feminista. Ano III, n9, Dez. 2011. Socialismo e Liberdade. Fundação Lauro Campos, 2011.

MENDONÇA, Maria Eloísa. Os efeitos perversos da precarização no mundo do trabalho feminino. In: Revista Feminista. Ano III, n9, Dez. 2011. Socialismo e Liberdade. Fundação Lauro Campos, 2011.

NAHNER, J. E. Emancipação do sexo feminino: a luta pelos direitos da mulher no Brasil, 1850-1940. Florianópolis: Ed. Mulheres; Santa Cruz do Sul: EDUNISC, 2003.

IANNI, O. Pensamento Social no Brasil. Bauru, SP: EDUSC, 2004.

WAISELFISZ, J. J. Mapa da violência 2012. Caderno complementar 1: homicídios de mulheres no Brasil. Disponível em: <http://mapadaviolencia.org.br/ pdf2012/mapa2012_mulher.pdf $>$. Acesso em: 01 jul. 2014.

WEBER, Max. Economia e sociedade: fundamentos da sociologia compreensiva. Tradução de Regis Barbosa e Karen Elsabe Barbosa; Revisão técnica de Gabriel Cohn - Brasília, DF : Editora Universidade de Brasília, 2000.

MOTA, A. E. A centralidade da assistência social na seguridade social brasileira nos anos 2000. In: MOTA, 
A. E. (Org.). 0 mito da assistência social: ensaios sobre Estado, política e sociedade. 2. ed. rev. e ampl. São Paulo: Cortez, 2008.

PATERMAN, C. O contrato sexual. São Paulo/Rio de Janeiro: Paz e Terra, 1993.

PISCITELLI, A. Reflexões em torno do gênero e feminismo. In: COSTA, C. de L.; SCHMIDT, S. P. (Orgs.). Poéticas e políticas feministas. Florianópolis: Editora Mulheres, 2004.

PORTAL R7 NOTÍCIAS. A cada 12 segundos uma mulher sofre violência no Brasil, informa Secretaria de Políticas para Mulheres. Disponível em: http://noticias. r7.com/brasil/a-cada-12-segundos-uma-mulher-sofreviolencia-no-brasil-informa-secretaria-de-politicaspara-mulheres-02082013. Acesso em: 01 jul. 2014

POULIN, R. Quinze teses sobre o capitalismo e o sistema mundial de prostituição. In: FARIA, N.; POULIN, R. (Org.). Desafios do livre mercado para o feminismo. São Paulo: Sempreviva Organização Feminista, 2005. p. 40-69.

REPÓRTER BRASIL. Tráfico de pessoas, mercado de gente. 2012. Disponível em: <http:// www.escravonempensar.org.br/wpcontent/ uploads/2013/03/cartilha_trafico_spread_WEB.pdf>. Acesso em: 01 jul. 2014

SAFFIOTI, H. I. B. Gênero, Patriarcado e violência. São Paulo: Editora Fundação Perseu Abramo, 2004.

SANTOS, S. M. de M.; OLIVEIRA, L. Igualdade nas relações de gênero na sociedade do capital: limites, contradições e avanços. Revista Katálysis, Florianópolis, v. 13, n. 1, p. 11-19, jan./jun. 2010.

SCOTT, Joan W. Gênero: uma categoria útil para análise histórica. New York, Columbia University Press. 1989. Disponível em: <http://disciplinas.stoa. usp.br/ pluginfile. php/6393/mod resource/content/1/ G\%C3\%AAnero-Joan\%20Scott.pdf>. Acesso em: 02 abr. 2012 